\title{
Al-Mg-Cu based alloys and pure Al processed by high pressure torsion: the influence of alloying additions on strengthening
}

\author{
Jiuwen Zhang ${ }^{1,2}$, Nong Gao ${ }^{1}$ and Marco J. Starink ${ }^{1}$, \\ ${ }^{1}$ Materials Research Group, School of Engineering Sciences, University of Southampton, \\ Southampton SO17 1BJ, United Kingdom \\ ${ }^{2}$ School of Materials and Engineering, Dalian University of Technology, Dalian, China, 116084
}

\begin{abstract}
The influence of alloying additions on strengthening of high pressure torsion (HPT) processed alloys was investigated using commercially pure $\mathrm{Al}$ (Al-1050 alloy) and five Al-(1-3) Mg-(0-4)Cu alloys (in $w t \%)$. Microhardness was measured on cross sections. For Al-1050 the microhardness reaches a peak at an effective strain of about 3 and subsequently decreases. The microhardness of Al-Mg-Cu alloys increases strongly and continuously with increasing equivalent strain. This workhardening rate is enhanced by increasing $\mathrm{Mg}$ content over the entire range of strain. Furthermore, the workhardening rates were higher in $\mathrm{Cu}$-free and low $\mathrm{Cu}$-containing $(\leq 0.4 \%) \mathrm{Al}-\mathrm{Mg}$ alloys as compared to high $\mathrm{Cu}-$ containing Al-Mg alloy at strains less than 3. The results indicate that dislocation-solute and dislocation-cluster interactions play an important role in strengthening.
\end{abstract}

Keywords: aluminium alloys; high pressure torsion; geometrically necessary dislocations; cold work; clusters

\section{Introduction}

Several severe plastic deformation (SPD) techniques have been applied widely to modify microstructures and produce ultra fine grained (UFG) materials with higher strength, improved formability and other favourable properties [1,2,3]. Among these techniques, considerable interest has developed in high pressure torsion (HPT) due to the advantage of refining the grain sizes of pure metals and alloys by introducing a continuous and rapid accumulation of high strain without interruption of straining. The microhardness and microstructural evolution occurring during HPT have been investigated extensively, and most attention has been paid to pure and commercially pure metals $[4,5,6,7,8,9,10]$. Some investigations focused on pure or high purity metals such as pure $\mathrm{Cu}$ [4], commercially pure $\mathrm{Ti}[5]$ and pure $\mathrm{Ni}[6,7]$. Pure metals are generally too weak for structural applications and therefore they are alloyed with several elements to improve its mechanical properties and inhibit grain growth. Although earlier reports, as mentioned above, described some factors influencing strengthening in pure metals and metallic alloys during SPD, there have been few systematic studies of the influence of alloying additions on strengthening in alloys during SPD.

In the present work we will investigate HPT processing of $\mathrm{Al}-\mathrm{Mg}-\mathrm{Cu}$ based alloys that have potential to be used as structural materials. The Al-Mg-Cu alloys with low $\mathrm{Cu}(<0.5 \mathrm{wt} \%)$ content that are being studied in this work span compositions of alloys that have been widely used in beverage cans for decades [11], to compositions that are now increasingly being used as car body panels to reduce weight and thus improve fuel economy and reduce emissions [12]. In these applications they derive their 
strength mostly from solution strengthening and strain hardening [13]. The Al-Mg-Cu alloys with higher $\mathrm{Cu}$ content $(>2.5 \mathrm{wt} \%)$ that are being studied in this work are applied predominantly in the aeronautical industry due to their in-service strength, which is due primarily to precipitation hardening $[14,15,16,17]$, combined with good damage tolerance properties [18]. Recent development in these types of alloys has seen the introduction alloys with Li at relatively low levels $(<2$ wt. \%) [19,20,21]. These $3^{\text {rd }}$ generation Al-Li alloys are now implemented on aircraft for lower wing skin, stringers, and fuselage skin as the disadvantages encountered on the first generations (reduced ductility, reduced fracture toughness and reduced thermal stability [22]) have been solved by an improvement of the chemical composition of the alloys and optimised thermo-mechanical treatments [19]. One of the alloys studied here is a low $\mathrm{Li}$ containing $\mathrm{Al}-\mathrm{Cu}-\mathrm{Mg}$ alloy, with composition close to those $3^{\text {rd }}$ generation AlLi alloys. In several aspects, it is the most advanced of the alloys studied, having the highest elastic modulus, the lowest density, and the highest specific fatigue resistance.

The alloys studied have a range of $\mathrm{Mg}$ contents. The influence of $\mathrm{Mg}$ content on grain refinement has been reported by Horita et al [23], who showed that the severe plastically deformed Al-3Mg had a smaller grain size about 4 times smaller than Al-1.5Mg. These effects were analysed in a model by Starink et al. [24], which indicated that the cause is the enhanced dislocation generation during SPD through addition of $\mathrm{Mg}$.

The objective of the work reported here is to evaluate the influence of alloying additions on strengthening by SPD in commercially pure aluminium and five Al-(1-3)Mg-(0-4)Cu alloys (in wt \%).

\section{Experimental materials and procedures}

Commercially pure Aluminium (Al-1050 alloy) and five Al-(1-3) Mg-(0-4) Cu alloys (in wt \%) were selected for this investigation and their compositions are shown in Table 1. Prior to HPT the materials had been subjected to the following processing. The Al-1050 had been extruded into a rod with grain size of $45 \mu \mathrm{m}$. The cast $\mathrm{Al}-1 \mathrm{Mg}, \mathrm{Al}-1 \mathrm{Mg}-0.4 \mathrm{Cu}$ and $\mathrm{Al}-3 \mathrm{Mg}-0.4 \mathrm{Cu}$ ingots were preheated and homogenised at $540^{\circ} \mathrm{C}$, and subsequently hot rolled down to $5 \mathrm{~mm}$ in thickness [13]. After that, the hot rolled sheets were solution treated at $500^{\circ} \mathrm{C}$ for 20 minutes, followed by cold rolling to $10 \%$ reduction, and grain size is about $30 \times 100 \mu \mathrm{m}$. The Al-1Mg-4Cu and $\mathrm{Al}-1 \mathrm{Mg}-2.7 \mathrm{Cu}-1 \mathrm{Li}$ alloys (the high $\mathrm{Cu}-$ containing Al-Mg alloys) were cast, hot rolled to plate, solution treated and subsequently aged at room temperature to T3 condition. The specimens for HPT having a diameter of $10 \mathrm{~mm}$ were sliced from extruded rod or rolling plate and mechanically polished to a thickness of $0.8 \mathrm{~mm}$. The Al-1Mg-4Cu is within the range of the $2024 \mathrm{Al}$ composition.

The HPT process was conducted on a facility with two anvils with a depression of $0.25 \mathrm{~mm}$ in depth and $10 \mathrm{~mm}$ in diameter, which is schematically shown in Fig. 1. The

disks were held in the depression and a lubricant of $\mathrm{MoS}_{2}$ was placed around the edges of the depression in order to reduce the friction between the upper and lower anvil. The specimens were pressed at a pressure of $3 \mathrm{GPa}$ and then torsion-strained at a rotation speed of $1 \mathrm{rpm}$ at room temperature (RT). Samples were deformed by HPT for a total of 5 turns. 
Table 1 Compositions of the alloys studied

\begin{tabular}{|c|c|c|c|c|c|c|c|c|}
\hline \multirow{2}{*}{ Alloy } & \multicolumn{8}{|c|}{ Composition, $\mathrm{wt} \%$} \\
\hline & $\mathrm{Mg}$ & $\mathrm{Cu}$ & $\mathrm{Mn}$ & $\mathrm{Fe}$ & $\mathrm{Si}$ & $\mathrm{Li}$ & $\mathrm{Zr}$ & $\mathrm{Al}$ \\
\hline Al-1Mg & 1.02 & $<.01$ & 0.25 & 0.22 & 0.16 & - & - & \\
\hline Al- $1 \mathrm{Mg}-0.4 \mathrm{Cu}$ & 1.03 & 0.39 & 0.26 & 0.20 & 0.14 & - & - & \\
\hline Al- $3 \mathrm{Mg}-0.4 \mathrm{Cu}$ & 2.9 & 0.4 & 0.25 & 0.19 & 0.15 & - & - & hal \\
\hline Al-1Mg-2.7Cu-1Li & 1.01 & 2.70 & - & - & - & 0.96 & 0.09 & \\
\hline $\mathrm{Al}-1 \mathrm{Mg}-4 \mathrm{Cu}$ & 1.37 & 4.34 & 0.42 & - & 0.14 & - & - & \\
\hline Al-1050 & - & 0.008 & 0.005 & 0.26 & 0.14 & - & - & \\
\hline
\end{tabular}

The influence of solution treatment and ageing was examined for the $\mathrm{Al}-1 \mathrm{Mg}-4 \mathrm{Cu}$ alloy under three types of treatments: a) 5 turns by HPT without solution and ageing treatment, b) solution heat treatment $\left(495^{\circ} \mathrm{C}\right.$ for 30 minutes) prior to 5 turns by HPT and c) solution heat treatment $\left(495^{\circ} \mathrm{C}\right.$ for 30 minutes) prior to 5 turns by $\mathrm{HPT}$, and subsequently aged at $150^{\circ} \mathrm{C}$ for 2 days.
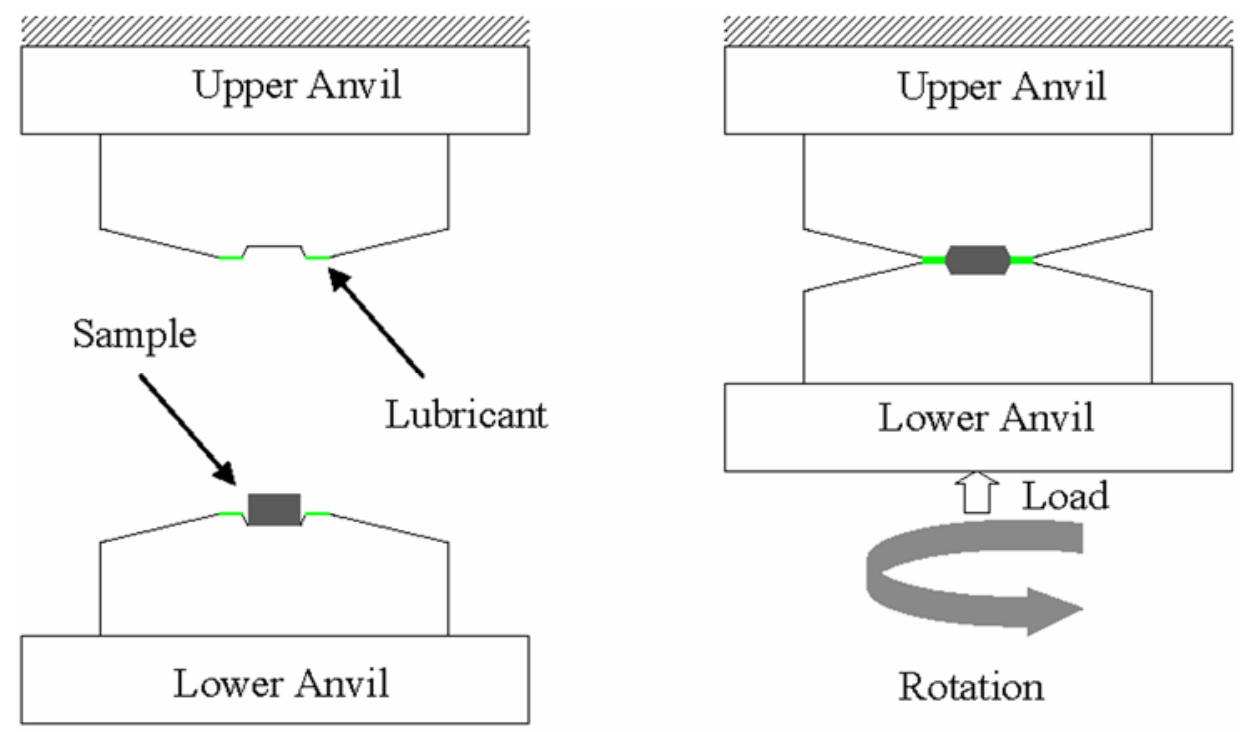

Fig. 1 Scheme of High pressure torsion tool and specimen [1]

The shear strain of disk subjected to HPT, $\gamma$, can be calculated by:

$$
\gamma=2 \pi N r / h
$$

where $N$ is the number of rotations, $r$ the distance of site of microhardness measurement from the centre of the sample and $h$ the thickness of disk. The precise true strain arising from HPT straining, and the extend to which this is homogeneous through the thickness direction, has not yet been fully understood, but we can usually use effective strain to compare the deformation in simple shear with linear strain produced by extension, drawing or rolling, because the principal shear stress acts at $45^{\circ}$ to the plane of the principal normal stress. Thus, the true strain can be expressed as $[25,26]$ :

$$
\varepsilon=\gamma / \sqrt{3}
$$


However, Eq. 2 is not valid for large strain, i.e. $\gamma>0.8$, because the directions of the maximum normal stress and strain in shear do not coincide, which can be proved by distorting a geometric square into a parallelogram and simultaneously a circle that initially inscribed in the original square into ellipse [25]. When ignoring the change in thickness of disk, the proper equation for equivalent strain at large strains is then given by [25]:

$$
\varepsilon=(2 / \sqrt{3}) \ln \left[\left(1+\gamma^{2} / 4\right)^{1 / 2}+\gamma / 2\right]
$$

Following HPT, disks were cut into halves in order to characterize cross sections. The sections were carefully ground up to 4000 -grit $\mathrm{SiC}$ paper and polished to a mirror-like finish with a $0.05 \mu \mathrm{m}$ colloidal silica suspension. The Vickers microhardness, Hv, was measured at about 30 positions distributed at regular intervals across a line through the centre of cross section of the disks by imposing a load of $300 \mathrm{~g}$ for $15 \mathrm{~s}$. Optical microscopy was used to observe the distribution of particles in selected Al-Mg$\mathrm{Cu}$ alloys.

TEM was conducted on HPT processed Al-1050 and the Al-1Mg-4Cu alloy. The HPT processed discs were ground to a thickness of $\sim 200 \mu \mathrm{m}$ in thickness and then TEM samples of $3 \mathrm{~mm}$ in diameter were punched out at three different regions of the disks. Subsequently, the samples were thinned to perforation using a two-jet electropolishing at $-30^{\circ} \mathrm{C}$ with an electrolyte solution of $\mathrm{HNO}_{3}$ : methanol $=1: 3$ (in volume). TEM foils were examined using a JEOL 3010 microscope operating at $300 \mathrm{kV}$.

\section{Results}

\subsection{The microhardness of HPT processed disks}

Fig. 2 shows the dependence of the Vickers microhardness of the investigated specimens on distance from the centre of disks. It can be seen that the hardness of the investigated specimens depend on alloying. In general terms, the Hv values of as-received alloys increased with increasing alloying contents and the highest $\mathrm{Hv}$ values were recorded for the Al-1Mg-4Cu alloy. The microhardness of Al$1050(>99.50 \% \mathrm{Al})$ samples after five turns by HPT initially increased from the centre to about $0.5 \mathrm{~mm}$ from the centre and then decreased slowly (Fig. 2a). This behaviour is significantly different from that in high purity $\mathrm{Al}$ [27]. This could be due to the interaction of strengthening due to increasing dislocation density with increasing radii, and recovery, which becomes dominant after dislocation densities reach a particular value. The results show that very small additions of Fe and Si can lead to a significant change of shape of the Hv vs. distance curve of Al.

Fig. $2 \mathrm{~b}$ shows that the microhardness of the three $\mathrm{Cu}$-free and low $\mathrm{Cu}(0.4 \mathrm{wt} \%) \mathrm{Al}-\mathrm{Mg}$ alloys initially rapidly increases from centre to about $1 \mathrm{~mm}$ and then slowly increases to reach a plateau near the periphery. After HPT processing, the Al- $1 \mathrm{Mg}-0.4 \mathrm{Cu}$ alloy has a slightly higher $\mathrm{Hv}$ than the $\mathrm{Al}-1 \mathrm{Mg}$ alloy, whereas the Al-3Mg-0.4Cu has a substantially higher $\mathrm{Hv}$ compared with the Al-1Mg and Al$1 \mathrm{Mg}-0.4 \mathrm{Cu}$ alloys. Fig. $2 \mathrm{c}$ presents the microhardness of high $\mathrm{Cu}$-containing Al-Mg alloys (Al-1Mg2.7Cu-1 Li and $\mathrm{Al}-1 \mathrm{Mg}-4 \mathrm{Cu}$ ). In the $\mathrm{Al}-1 \mathrm{Mg}-2.7 \mathrm{Cu}-1 \mathrm{Li}$ alloy the $\mathrm{Hv}$ increases approximately linearly with increasing distance from the centre, to reach a maximum of $225 \mathrm{Hv}$. In the Al-1Mg-4Cu alloy the $\mathrm{Hv}$ initially rapidly increases from the centre to about $2 \mathrm{~mm}$ from the centre and then the rate slightly 
decreases. No plateau can be observed near the periphery in the two high $\mathrm{Cu}$-containing Al-Mg alloys and the hardness continues rising substantially up to the edge of the sample.

Fig. $2 \mathrm{~d}$ shows the Hv increment due to HPT processing. The Hv increment for Al-1050 is larger than that for high purity Al, again highlighting the substantial influence of small additions of Fe and $\mathrm{Si}$. In terms of the distribution of $\mathrm{Hv}$ increment, there is no clear difference between $\mathrm{Al}-1 \mathrm{Mg}$ and $\mathrm{Al}-1 \mathrm{Mg}-$ $0.4 \mathrm{Cu}$, whereas the higher $\mathrm{Hv}$ increment was observed in $\mathrm{Al}-3 \mathrm{Mg}-0.4 \mathrm{Cu}$. The results show that $\mathrm{Mg}$ strongly increases the hardening due to HPT processing.
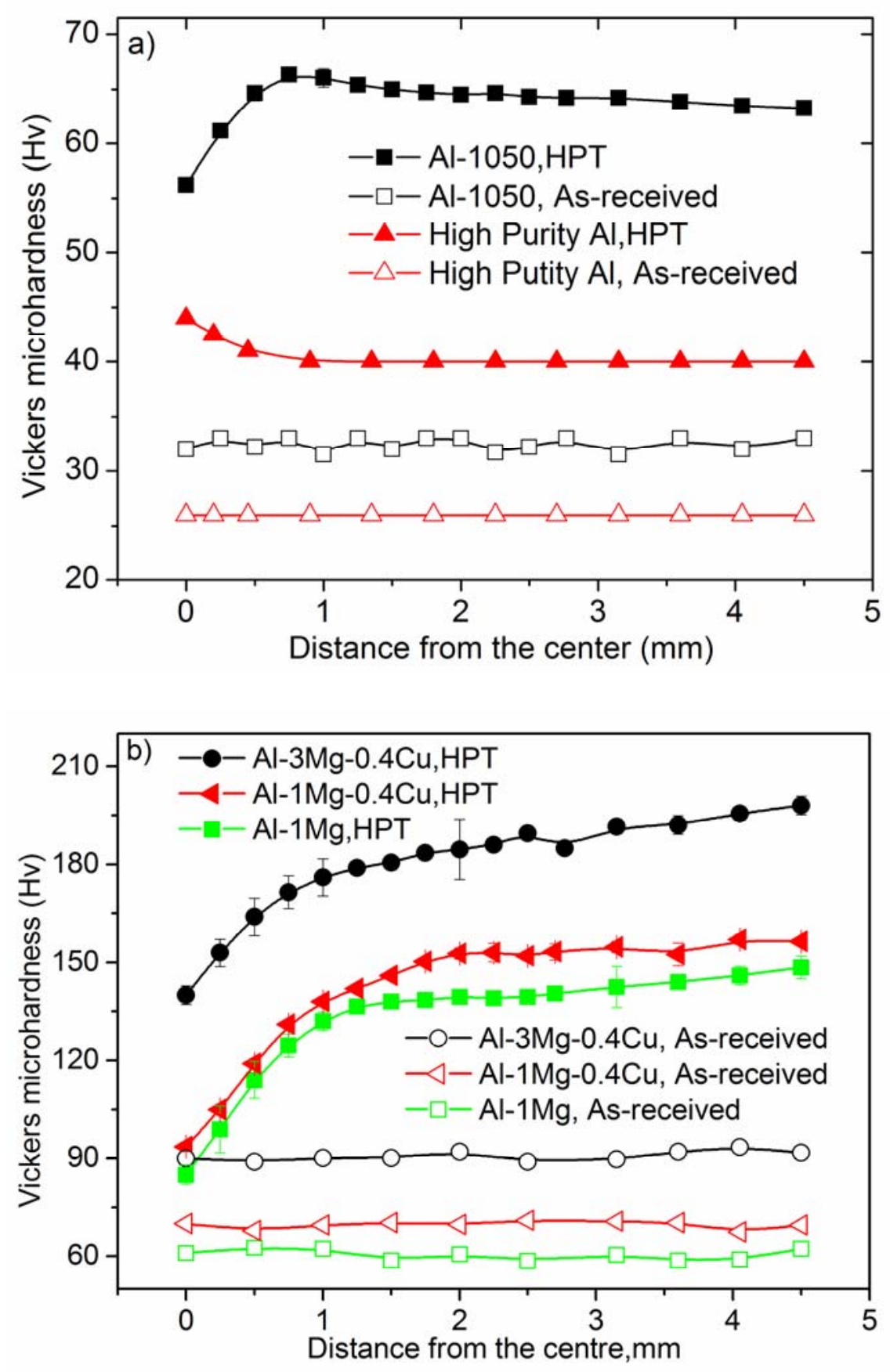

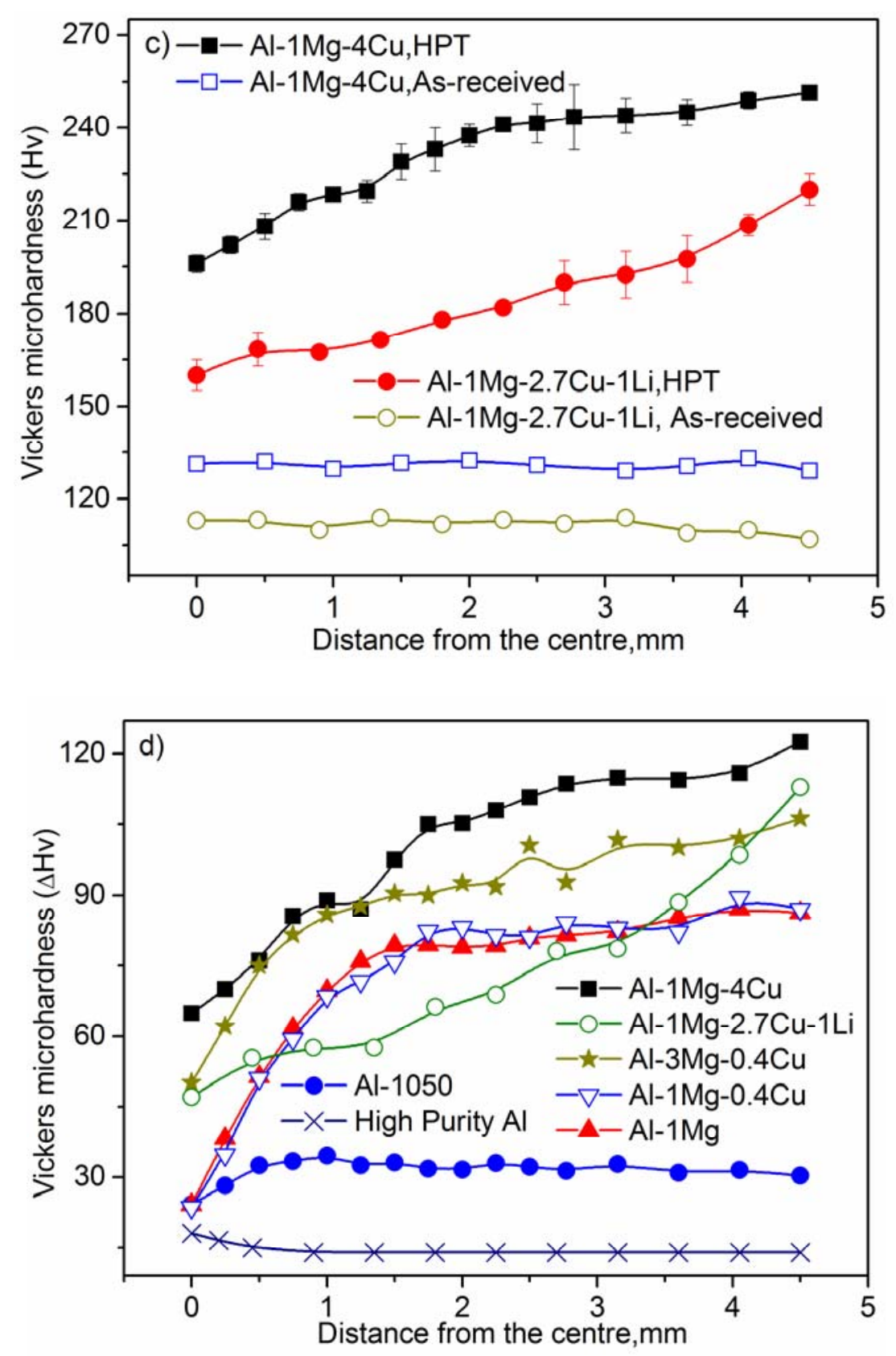

Fig. 2 Vickers microhardness vs. distance from centre of HPT disks for, a) high purity pure Al (data taken from [27]), Al-1050; b) Cu-free and low Cu-containing Al-Mg alloys; c) high Cu-containing Al$\mathrm{Mg}$ alloys; d) $\mathrm{Hv}$ increment for all alloys studied

The influence of compression on microhardness during HPT processing was investigated for the Al$1 \mathrm{Mg}$ alloy. A sample was compressed at a pressure of $3 \mathrm{GPa}$ without torsion straining for $5 \mathrm{~min}$ (the duration of 5 HPT rotations) and the results show that the compression contributes to microhardness by about $3 \mathrm{Hv}$.

In $\mathrm{Cu}$-free and low $\mathrm{Cu}$-containing alloys processed by $\mathrm{HPT}, \mathrm{Hv}$ increases rapidly from centre to a radius of $\sim 1.5 \mathrm{~mm}$, and hence there is substantial inhomogeneity in the mechanical properties at the central region of the disks. In the centre of the disc the strain due to rotation is zero, and only 
compression contributes to deformation. However, the hardness increment in the centre (about 15-65 MPa for the alloys studied, see Fig. 2d) is much higher than that can be expected from compressive strain alone. As will be explained below, the hardening in the centre is due to the accumulation of geometrically necessary dislocations (GNDs) due to a large strain gradient. In addition, the plastic zone under the Vickers hardness tester is of finite size (indentation is a square with diagonals of about $20 \mu \mathrm{m}$ at an indentation load of $10 \mathrm{~g}$ ), and thus the hardness obtained reflects this zone. At the outer periphery, the $\mathrm{Hv}$ increases only slightly as a function of increasing radius.

Fig. 3 shows the dependence of the Vickers microhardness of investigated specimens on equivalent strain. In the Al-1050 alloy, the Hv vs. effective strain plot appears to become very flat across the disks. Careful observation shows that at a strain of $\sim 3$ a maximum in hardness occurs. The Al-Cu-Mg alloys show a slight rise of microhardness as a function of equivalent strain at relatively low equivalent strain $\varepsilon \leq 3$; however, in the strain range $\varepsilon>3$, the HPT deformation resulted in a sharp rise of microhardness with increasing strain. A careful inspection of Fig. 3 reveals that at a relatively low equivalent strain $\varepsilon \leq$ 3 the $\mathrm{Cu}$-free and low $\mathrm{Cu}$-containing alloys possess quicker rise of microhardness with strain than high $\mathrm{Cu}$-containing alloys. Three parallel dotted lines schematically show the difference of workhardening of Al-Mg-Cu alloys in the strain range $\varepsilon<3$. On the other hand, in the strain range $\varepsilon>3$, the workhardening rate of $\mathrm{Cu}$-free and low $\mathrm{Cu}$-containing $\mathrm{Al}-\mathrm{Mg}$ alloys decreased with increasing equivalent strain. By contrast, the workhardening rate of high $\mathrm{Cu}$-containing alloys increased with increasing equivalent strain. These may be due to the presence of $\mathrm{Cu}-\mathrm{Mg}$ co-clusters in the $\mathrm{Al}-\mathrm{Mg}-\mathrm{Cu}$ alloy [28,29] (see Discussion). Contrary to above three cases, in high purity aluminium, Hv is highest at the centre of the disc, i.e. at very small strains [27].

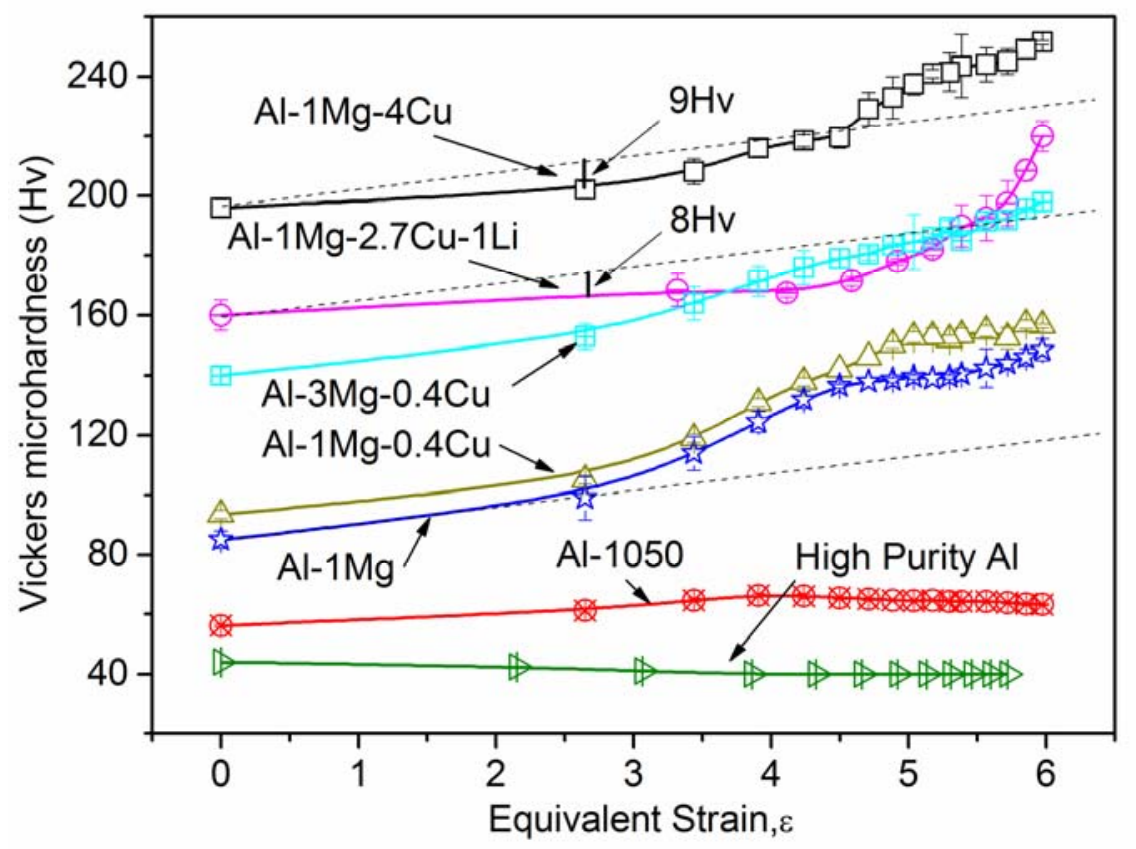

Fig. 3 Vickers microhardness vs. equivalent strain for high purity pure Al (data taken from [27]), Al1050 and $5 \mathrm{Al}-\mathrm{Mg}-\mathrm{Cu}$ based alloys processed by HPT. The dotted parallel lines are guides to show averaged trends. 


\subsection{Microstructural observations of disks subjected to HPT}

Fig. 4 shows an optical micrograph of the Al-1Mg-4Cu alloy deformed by HPT to 5 turns. The lower surface and upper surface of disk are designated on the graph by mark L and U. They are contacted with the lower anvil (rotating) and upper anvil (stable) of the HPT machine when the disk is deformed. The grain boundaries are not visible in this optical micrograph of a lightly etched specimen. Instead, the observed contrast is mainly due to intermetallic particles in the alloy. Earlier work has identified these particles as $\mathrm{Al}_{7} \mathrm{Cu}_{2} \mathrm{Fe}$ and $\mathrm{Al}_{2} \mathrm{CuMg}[30,31,32]$. Fig. 4 shows that the HPT produced a redistribution of intermetallic particles which were initially in straight bands parallel to the rolling direction, which is in the plane of the HPT disc. The microstructure can broadly be classified into 3 different deformation zones according the particle size and the direction of banded distribution of particle: a zone with coarser nonuniform particles (marked by A), a zone with finer uniform particles (marked by C) and a transition zone (marked by B). Moreover, there are slightly different contrast between optical microstructures of two half cross sections.

It is very interesting to note that the patterns of bands of intermetallic particles are always at an angle to what are often implicitly assumed to be the symmetry axes of torsional rotation. The present results show that in contrast to these assumptions in earlier works on HPT, deformation depends not just on distance from the axis of rotation but also on distance from the lower platen.

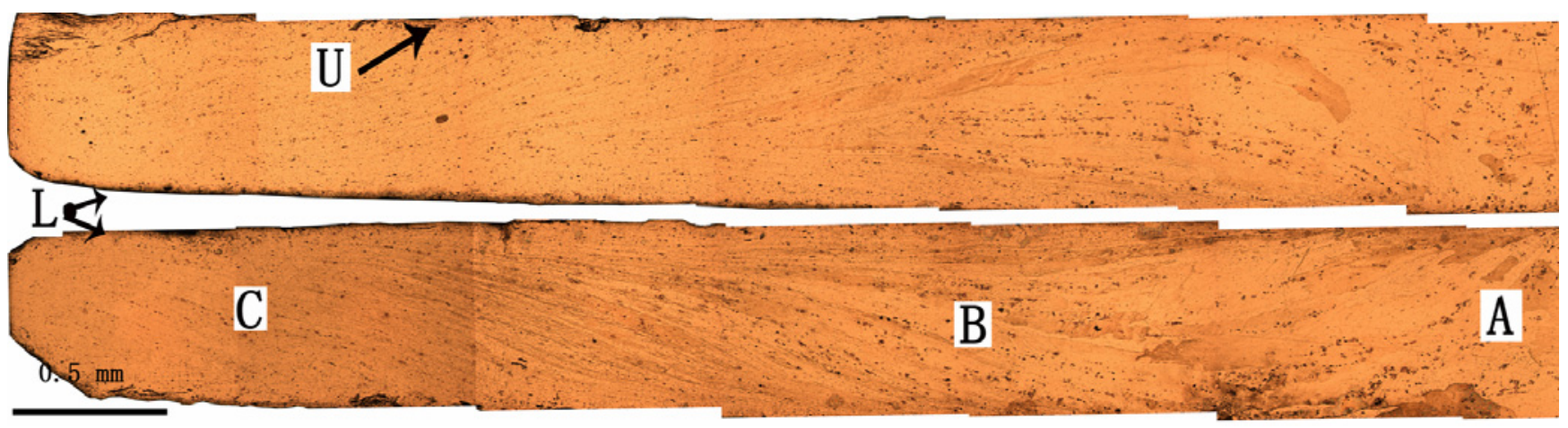

Fig. 4 Optical microstructure of a cross section of the Al-1Mg-4Cu disk subjected to HPT. L denotes lower surface and $\mathrm{U}$ denotes upper surface.

The TEM micrographs of Al-1050 alloy at about $1 \mathrm{~mm}\left(\varepsilon_{\text {eq }}=4.2\right), 2.5 \mathrm{~mm}\left(\varepsilon_{\text {eq }}=5.3\right)$ and $4 \mathrm{~mm}\left(\varepsilon_{\text {eq }}\right.$ $=5.8$ ) from the centre of disk are shown in Fig. 5a-c, respectively. The HPT processed samples show slightly different structure from centre to outer region of disk. From Fig. 5a it can be observed that there are some very fine grains with a size of about 100-200nm, and the grain boundaries are curved and wavy. A high dislocation density was observed at grain boundaries and inside some grains (Fig. 5a). Averaging over several TEM micrographs provided a grain size of $0.6 \mu \mathrm{m}$ in the centre. At effective strain 5.3 (Fig. 5b), somewhat larger grains and lower density of dislocations was observed. Free dislocation density at grain boundaries and distortions and bending of the lattice fringes were observed at the $4 \mathrm{~mm}$ position (Fig. 5c). 


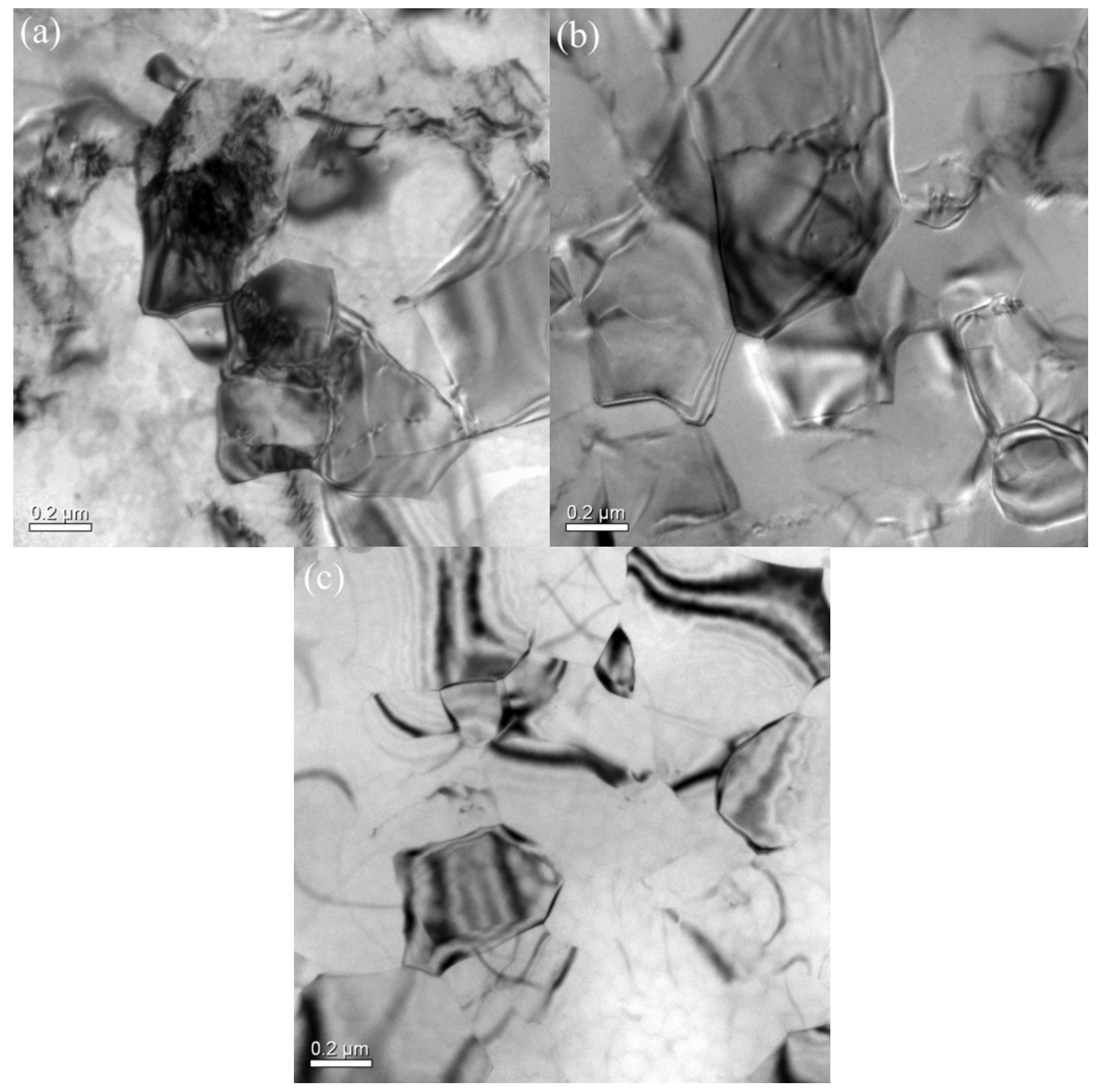

Fig. 5 TEM of Al-1050 by m-HPT for 5 turns: a) at $1 \mathrm{~mm}$ from the centre of the disk $\left(\varepsilon_{\text {eq }} \approx 4.2\right)$; b) at $2.5 \mathrm{~mm}$ from the centre of the disk ( $\left.\left.\varepsilon_{\text {eq }} \approx 5.3\right) ; \mathrm{c}\right)$ at $4 \mathrm{~mm}$ from the centre of the disk $\left(\varepsilon_{\text {eq }} \approx 5.8\right)$

Fig. 6 shows the typical TEM microstructure observations of Al-1Mg-4Cu samples after HPT straining under different heat treatment conditions. The TEM graphs were taken at the region about $4 \mathrm{~mm}$ away from the disk centre $\left(\varepsilon_{\text {eq }}=5.8\right)$. HPT introduced a high density of dislocations in the Al-1Mg- $4 \mathrm{Cu}$ alloy (Fig. 6a) and the grain boundaries were often ill-defined. Fig. 6b shows the TEM microstructure adjacent to the centre of disk at about $1 \mathrm{~mm}\left(\varepsilon_{\text {eq }}=4.2\right)$. At this location a large grain consisting of several subgrains with near parallel subgrain boundaries were observed. In order to investigate the thermal stability and the influence of HPT straining on precipitates, additional experiments were conducted. It can be seen that the microstructure subjected to solution treatment at $495^{\circ} \mathrm{C}$ for 30 
minutes prior to HPT is similar to the results without solution treatment. It is difficult to define grain size from TEM graphs (Fig. 6a and c). Another disk was subjected to solution heat treatment $\left(495^{\circ} \mathrm{C}\right.$ for 30 minutes) and subsequently processed to 5 turns by HPT and then aged at $150{ }^{\circ} \mathrm{C}$ for 2 days. The TEM microstructure shown in Fig. 6d reveals dislocation cells and dislocation-tangles in the heavily deformed grains of the alloy. The ageing at $150^{\circ} \mathrm{C}$ appeared to have caused a decrease in the dislocation density. In this image, the grain size was estimated to be about $300 \mathrm{~nm}$. Grain boundaries are mostly poorly defined, but some grain boundaries are identifiable and a portion of these are still curved or wavy, which indicate a non-equilibrium state [23].

\section{Discussion}

The results show that whilst HPT processing increased hardness in all alloys, the magnitude and rate of this increase is strongly influenced by alloying additions over a wide range of strain.

\subsection{The evolution of microstructure in pure Al during HPT}

Prior to HPT, Al-1050 has low hardness $(\sim 30 \mathrm{Hv})$, and the limited strengthening compared to high purity $\mathrm{Al}$ is predominantly due to solid solution strengthening. After HPT, the grain was dramatically refined and the hardness was increased. The central and outer regions of the HPT disk (Fig. 5) show markedly different microstructures. Elongated grains are typical results of monotonic HPT straining [33] and ECAP [34] especially with deformation route C. It is well known that both the applied pressure $(\mathrm{P})$ and the number of revolutions $(\mathrm{N})$ influence the development of microhardness in HPT [5, 7] and larger numbers of turns and/or higher pressure applied to disks can produce a more homogeneous microstructure.

It is instructive to compare the results obtained on Al-1050 in this investigation after rotation by HPT for 5 turns with data reported earlier for other pure metals. In the literature, the grain size measured for pure $(99.96 \%) \mathrm{Cu}$ deformed by HPT $(P=6 \mathrm{GPa}, N=5)$ is $440 \mathrm{~nm}$ in the centre region and $200 \mathrm{~nm}$ in the outer region [35], and few coarse grains were also observed in higher purity $\mathrm{Cu}(99.98 \%)$ [4]. The grain size of pure $(\geq 99.98 \%) \mathrm{Ni}$ deformed by HPT $(P=9 \mathrm{GPa}, N=5)$ increased from $200 \mathrm{~nm}$ in the centre $\left(\varepsilon_{\text {eq }}\right.$ $\cong 4.2$ ) to $400 \mathrm{~nm}$ at the edges ( $\varepsilon_{\text {eq }} \cong 5.8$ ) [7], and other studies using $0.3 \mathrm{~mm}$ thick disks showed finer grain sizes of 200nm $(P=7 \mathrm{GPa}, N=5)[36]$ and $260 \mathrm{~nm}(P=6 \mathrm{GPa}, N=5)$ [6] at the periphery (equivalent strain of about 7); and for CP Ti Grade 4 subjected to HPT $(P=6, N=10)$, the grain size is about $160 \mathrm{~nm}$ [37]. All of the above mentioned grain sizes were recalculated by the method described in [38] and these pure metals attained a much finer grain size than high purity Al or our HPT processed Al-1050 alloy.

From the analysis of the TEM micrograph of Al-1050 alloy (Fig. 5), it is important to note that the density of dislocations at grain boundaries decreased with an increasing strain along the radius of disks, which suggest that the annihilation of dislocations in the periphery of disk is faster than in the centre area during HPT processing. This could be related to the presence of geometrically necessary dislocations which are generated to accommodate the strain gradient (implying lattice curvature) 
resulting from strain gradient during HPT processing. GNDs carry the same sign, which can not be mutually annihilated. At the centre region, the GNDs govern the hardening. At the outer region, the saturation of hardness was related to a saturation of total density of dislocation, in which the large sum of statistical stored dislocation (SSDs) with opposite signs can easily annihilate due to high stacking fault energy. Thus, these are believed to be responsible for the corresponding increase in grain sizes with increasing strain along the radius of disks subjected to HPT.

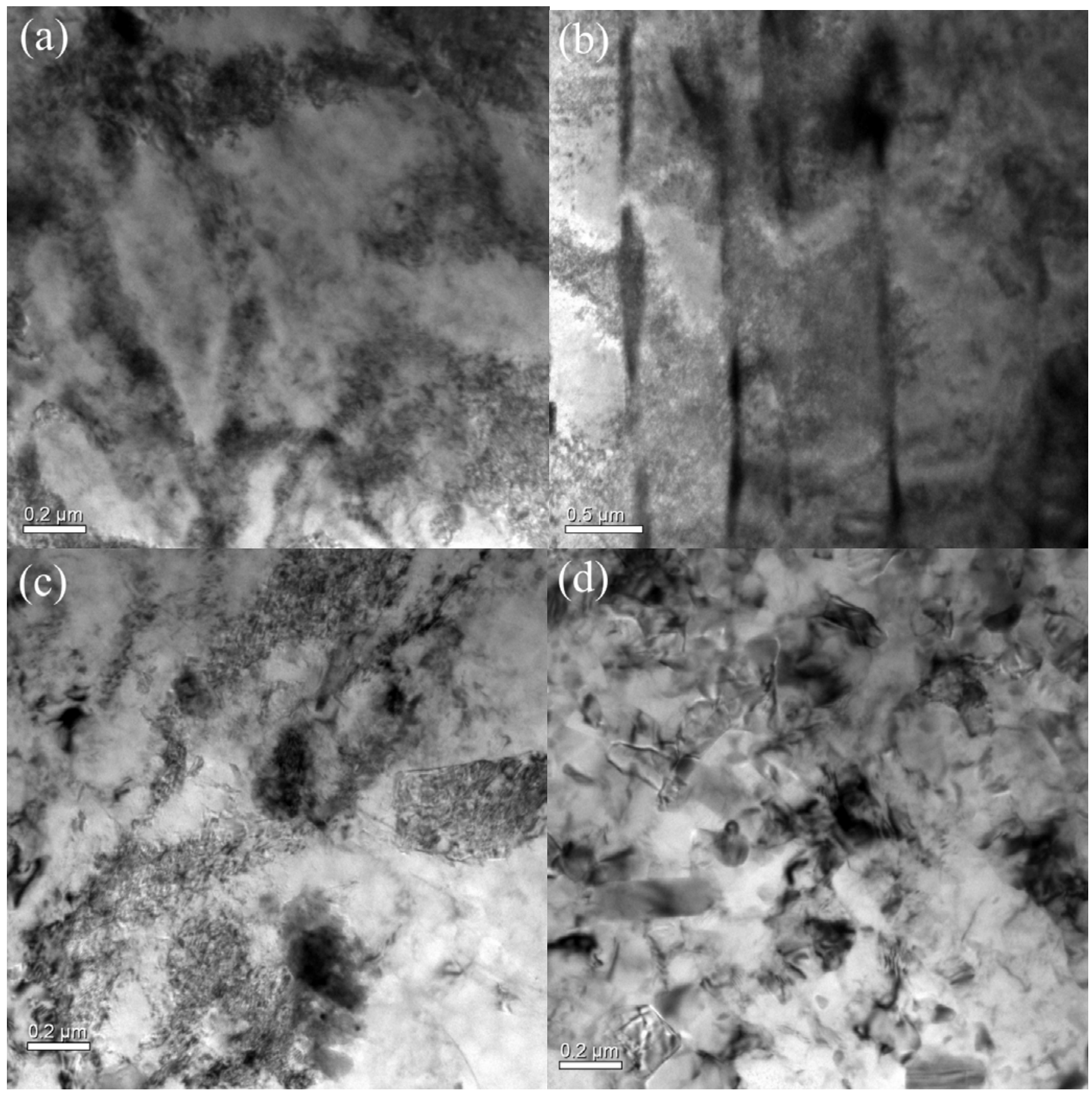

Fig. 6 Dislocation structures of the $\mathrm{Al}-1 \mathrm{Mg}-4 \mathrm{Cu}$ alloy at $4 \mathrm{~mm}$ from the centre of the disk: a) after 5 turns HPT $\left(\varepsilon_{\text {eq }} \approx 5.8\right) ;$ b) large grain with subgrains after 5 turns $\left.\operatorname{HPT~}\left(\varepsilon_{\text {eq }} \approx 4.2\right) ; \mathrm{c}\right)$ after $495^{\circ} \mathrm{C}$ solution treatment for 30 minutes +5 turns HPT $\left(\varepsilon_{\text {eq }} \approx 4.2\right)$; d) after $495^{\circ} \mathrm{C}$ solution treatment for 30 minutes +5 turns $\mathrm{HPT}+150^{\circ} \mathrm{C}$ ageing for 2 days $\left(\varepsilon_{\text {eq }} \approx 5.8\right)$ 
In this work, higher dislocation density was observed in the centre of Al-1050 alloy compared with high purity aluminium [27]. This could be due to a low volume of intermetallic phases at grain boundaries in the $1 \mathrm{XXX}$ series $\mathrm{Al}$ alloy, which are binary $\mathrm{Al}_{x} \mathrm{Fe}$ and ternary $\mathrm{Al}-\mathrm{Fe}-\mathrm{Si}[39,40]$. These particles can be broken up and a low volume fraction of Al-Fe-Si precipitates were also observed after ECAP [41], which may inhibit the movement of dislocation during severe plastic deformation. In addition, they may be partially dissolved during SPD. Supporting the latter is the observation by Korchef et al. [42] that the lattice parameter of the Al-rich phase in Al 1100 alloy decreased during ECAP processing, which may be due to the dissolution of elements such as Si and Fe.

\subsection{The evolution of microstructure in Al-Mg-Cu alloys during HPT}

Addition of $0.4 \mathrm{wt} \% \mathrm{Cu}$ to $\mathrm{Al}-1 \mathrm{Mg}$ causes a small improvement in strength and hardness both in solution treated and subsequently rolled condition (see [13]). The present results also show that after severe plastic deformation using HPT, the $\mathrm{Cu}$ addition increases hardness slightly (Fig. 2b). The magnitude of this difference seems to be independent of strain. However, increasing the Mg content from 1 to $3 \mathrm{wt} \%$ causes a much stronger rise of microhardness, which indicates $\mathrm{Mg}$ addition can effectively improve strengthening during HPT processing. Previous studies reported that the strength of Al-Mg-Cu alloys increases approximation linearly with $\mathrm{Mg}$ content $[13,24]$. In the present SPD alloys also the interaction between $\mathrm{Mg}$ content and dislocations is important. High density of dislocations have been widely observed in Al-Mg alloys subjected to ECAP and the density increased with increasing $\mathrm{Mg}$ content [43]. A previous study [44], showed that an Al-Mg-Sc-Zr alloy processed by HPT up to half turn contains a high density of dislocations $\left(16 \cdot 10^{14} \mathrm{~m}^{-2}\right)$ in the periphery of disk (having a radius of $15 \mathrm{~mm}$ and a thickness of $0.5 \mathrm{~mm}$ ), which did not significantly change on increasing straining beyond five turns. In fact, Horita et al. [23] also reported the grain boundaries in Al-Mg alloys produced by severe plastic deformation are in high-energy nonequilibrium configuration.

In the present investigations, the major difference observed between the low $\mathrm{Cu}$-containing $\mathrm{Al}-\mathrm{Mg}$ alloys and high Cu-containing $\mathrm{Al}-\mathrm{Mg}$ alloys was the rate of workhardening, which was faster in the lower $\mathrm{Cu}$-containing $\mathrm{Al}-\mathrm{Mg}$ alloys during initial stages of strain (less than 3) and slower at higher strain levels (strains in excess of 3). Our high $\mathrm{Cu}$-containing Al-Mg alloys processed to 5 turns show a consistently fast increase over a wide range from the centre to edge of HPT processed disk and no saturation of hardness was observed under the present conditions. This is different from many other alloys (e.g. austenitic steel and a titanium [9,45]), where saturation occurred near the periphery of disks processed for at least 2 turns. The optical microscopy of $\mathrm{Al}-1 \mathrm{Mg}-4 \mathrm{Cu}$ (Fig. 4) combined with $\mathrm{Hv}$ distribution along the diameter (Fig. 2), suggests that the alloy exhibits significant inhomogeneity after HPT for 5 turns, where the sizes of intermetallics decreased gradually with increasing distance from the centre. TEM results (Fig. 6a and d) also demonstrated that there exists significant difference in microstructure between different areas. 
Some of the strengthening effects, especially in the alloys with significant $\mathrm{Cu}$, will be due to nanoscale precipitates. There have been some controversies over the precipitates in these $\mathrm{Al}-\mathrm{Cu}-\mathrm{Mg}$ alloys regarding to the ageing sequence and crystal structure, but recent work has demonstrated that $\mathrm{Cu}-\mathrm{Mg}$ clusters dominate the strengthening during the initial ageing including room temperature aged alloys [29]. (Mg-Cu co-clusters can not be resolved in TEM, but can be resolved by 3 dimensional atom probe $[29,46,47]$.) Although the HPT processed Al-1Mg-4Cu alloy has a high dislocation density which might stimulate nucleation of semicoherent precipitates ( $S$ or $S$ ' phase $[14,48]$ ), no such precipitates were observed in the aged $\mathrm{Al}-1 \mathrm{Mg}-4 \mathrm{Cu}$ sample. Hence the $\mathrm{Cu}-\mathrm{Mg}$ clusters played an important role in strengthening of Al-1Mg-4Cu subjected to HPT.

Compared with low $\mathrm{Cu}$-containing $\mathrm{Al}-\mathrm{Mg}$ alloys, there seems to be only a limited strengthening effect in $\mathrm{Al}-1 \mathrm{Mg}-2.7 \mathrm{Cu}$ by HPT over intermediate strain range. This may be explained by the interaction of co-clusters and dislocation during deformation, as follows. The order strengthening effect from cocluster can be approximated as [29]:

$$
\Delta \tau_{\mathrm{SRO}}=\frac{\gamma_{\mathrm{SRO}}}{b}=\frac{\Delta H_{\mathrm{A}-\mathrm{B}}}{b^{3}} \times \frac{4}{\sqrt{3}}\left[\frac{2}{3}\left(y_{\mathrm{A}}+y_{\mathrm{B}}\right)-\left(\frac{2}{3} x_{\mathrm{B}} y_{\mathrm{A}}+\frac{2}{3} x_{\mathrm{A}} y_{\mathrm{B}}+2 x_{\mathrm{A}} x_{\mathrm{B}}\right)\right]
$$

where $\gamma_{\mathrm{SRO}}$ is the change in energy per unit area on slip planes, $\Delta H_{\mathrm{A}-\mathrm{B}}$, the enthalpy of the nearest neighbour bond, $y_{\mathrm{A}}$, the amount of $\mathrm{A}$ atoms in the co-clusters, $y_{\mathrm{B}}$, the amount of $\mathrm{B}$ atoms in the coclusters, $x_{\mathrm{A}}$, the amount of $\mathrm{A}$ atoms in the Al-rich phase, $x_{\mathrm{B}}$, the amount of $\mathrm{B}$ atoms in the Al-rich phase. It was demonstrated [29] that in $\mathrm{Al}-\mathrm{Mg}-\mathrm{Cu}$ alloys the $\mathrm{Cu}-\mathrm{Mg}$ co-clusters can form very quickly and harden the alloy. The strengthening for the present Al-1M-Cu alloy is about $300 \mathrm{MPa}$. At the onset of straining, the $\mathrm{Cu}-\mathrm{Mg}$ co-clusters, inhibit the movement of dislocations, increasing the strength. However, co-clusters are shearable, and as straining proceeds, the moving dislocations will destroy $\mathrm{Cu}-$ $\mathrm{Mg}$ co-clusters (and to a lesser extend may generate some new ones). The net effect is a decrease in the strengthening contribution due to co-clusters. This effect is thought to be the main cause for the limited work hardening in the strain range up to about 4 in the alloys containing substantial $\mathrm{Cu}$ (see Fig. 3). In this view the continuous destruction of co-clusters is completed at strain of about 4, and hence on further increase of strain an increased work hardening will occur. The latter is evident in Fig. 3. 


\section{Conclusions}

In the present study, the influence of alloying additions on strengthening in high pressure torsion (HPT) process was investigated using pure Al (Al-1050 alloy) and five Al-(1-3)Mg-(0-4)Cu alloys (in wt\%). The Vickers microhardness was measured along diameters in each disk and the microstructural changes were studied in the Al-1050 and Al-1Mg-4Cu alloys. The following main conclusions can be drawn:

The microhardness of the Al-1050 aluminium alloy subjected to HPT reaches a peak at a strain of about 3 and subsequently decreases. The smaller grain size was observed in centre region of disk.

The microhardness of $\mathrm{Al}-\mathrm{Mg}-\mathrm{Cu}$ alloys increases drastically and continuously with increasing equivalent strain and $\mathrm{Mg}$ increases the workhardening rate of the $\mathrm{Al}-\mathrm{Mg}-\mathrm{Cu}$ alloys over the entire range of strain.

The hardness of two high $\mathrm{Cu}-$ containing $\mathrm{Al}-\mathrm{Mg}$ alloys increases approximately linearly with the distance from centre of disk. At stains less than 3, the workhardening rates were higher in $\mathrm{Cu}$-free and low $\mathrm{Cu}$-containing $\mathrm{Al}-\mathrm{Mg}$ alloy than in high $\mathrm{Cu}$-containing $\mathrm{Al}-\mathrm{Mg}$ alloy. By contrast, as straining proceeds, higher workhardening rates were observed in high $\mathrm{Cu}$-containing $\mathrm{Al}-\mathrm{Mg}-\mathrm{Cu}$ alloys. The differences indicate the existence of $\mathrm{Cu}-\mathrm{Mg}$ co-clusters influence the strengthening effect of $\mathrm{Al}-\mathrm{Mg}-\mathrm{Cu}$ alloy during HPT processing.

\section{Acknowledgements}

This work was partly supported by EPRSC under Grant No EP/D00313X/1. One of the authors (JWZ) thanks the China Scholarship Council (CSC) for financial support. We are grateful for the help of Mr. Rob Bowyer and Dr. Shuncai Wang with sample preparation and TEM experiments, and Mr JhengSyun Lee for assistance with sample preparation. Prof. T.G. Langdon is gratefully acknowledged for valuable discussions on SPD and HPT. 


\section{References}

[1] A.P. Zhilyaev, T.G. Langdon, Prog. Mater. Sci. 53 (2008) 893-979.

[2] R.Z. Valiev, T.G. Langdon, Prog. Mater. Sci. 51 (2006) 881-981.

[3] N. Tsuji, Y. Saito, H. Utsunomiya, S. Tanigawa, Scripta Mater. 40 (1999) 795-800.

[4] N. Lugo, N. Llorca, J.M, Cabrera, Z. Horita, Mater. Sci. Eng. A 477 (2008) 366-371.

[5] Y. Todaka, M. Umemoto, A. Yamazaki, J. Sasaki, K.Tsuchiya, Mater. Trans. 49 (2008) 7-14.

[6] Z.Q. Yang, U. Welzel, Mater. Letter 59 (2005) 3406-3409.

[7] A.P. Zhilyaev, G.V. Nurislamova, B.K. Kim, M.D. Baro, J.A. Szpunar, T.G. Langdon, Acta Mater. 51 (2003) 753-765.

[8] F. Wetscher, A. Vorhauer, R. Pippan, Mater. Sci. Eng. A 410 (2005) 213-216.

[9] A. Vorhauer, R. Pippan, Scr. Mater. 51 (2004) 921-925.

[10] J.M. Garcia-Infanta, A.P. Zhilyaev, A. Sharafutdinov, O.A. Ruano, F. Carreno, J. Alloys Compounds 473 (2009) 163-166.

[11] J. Courbon, Scripta Mater. 48 (2003) 1519 -1524.

[12] G.B.Burger, A.K. Gupta, P.W. Jeffrey, D.J. Lloyd, Mater. Charact. 35 (1995) 23.

[13] Z. Zhu, M.J. Starink, Mater. Sci. Eng. A 488 (2008) 125-133.

[14] S.C. Wang, M.J. Starink, N. Gao, Scripta Mater. 54 (2006) 287-291.

[15] M.J. Starink, P. Wang, I. Sinclair, P.J. Gregson, Acta Mater. 47 (1999) 3841-3853.

[16] I.N. Khan, M.J. Starink, J.L. Yan, Mater. Sci. Eng. A 472 (2008) 66-74.

[17] N. Gao, M.J. Starink, L. Davin, A. Cerezo, S.C. Wang,P.J., Mater. Sci. Tech. 21 (2005) 10101018 .

[18] N. Kamp, N. Gao, M.J. Starink, I. Sinclair, Int. J. Fatigue 29 (2007) 869-878.

[19] C. Giummarra, B. Thomas, R.J. Rioja. Proceedings of the Light Metals Technology Conference 2007, Canada.

[20] M.A. Munoz-Morris, I. Gutierrez-Urrutia, N. Calderon, D.G. Morris, Mater. Sci. Eng. A 492 (2008) 268-275.

[21] M.J. Starink, N. Gao, N. Kamp, S.C. Wang, P.D. Pitcher, I. Sinclair, Mater. Sci. Eng. A 418 (2006) 241-249.

[22] M.J. Starink, A.J. Hobson, I. Sinclair, P.J. Gregson, Mater. Sci. Eng. A 289 (2000) 130-142.

[23] Z. Horita, S.J. David, F. Minoru, N. Minoru, R.Z. Valiev, T.G. Langdon, J. Mater. Res. 11(1996) 1880-1890.

[24] Z. Zhu, M.J. Starink, Mater. Sci. Eng. A 489 (2008) 138-149.

[25] N.H. Polakowski, E.J. Ripling, Strength and structure of engineering materials, Englewood Cliffs, NJ: Prentice-Hall, 1966.

[26] R.Z. Valiev, Y.V. Ivanisenko, E.F. Rauch, B. Baudelet, Acta Mater. 44 (1996) 4705-4712.

[27] X. Cheng, Z. Horita, T.G. Langdon, Acta Mater. 56 (2008) 5168-5176.

[28] S.P Ringer, K. Hono, T. Sakurai, I.J. Polmear, Scripta Mater. 36 (1997) 517-521.

[29] M.J. Starink, S.C. Wang, Acta Mater. 57 (2009) 2376-2389.

[30] S.C. Wang, F. Lefebvre, J.L. Yan, I. Sinclair, M.J. Starink, Mater. Sci. Eng. A 431 (2006) 123136.

[31] S.C. Wang, M.J. Starink, Int. Mater. Rev. 50 (2005) 193-215.

[32] M.J. Starink, S.C. Wang, Scripta Mater., in press (2010).

[33] A.M. Andrei, B.S. Boris, G.P. Svetlana, V.D. Sergei, B. Brigitte, J. Mater. Sci. 43 (2008) 38003805.

[34] A. Mishra, B.K. Kad, F. Gregori, M.A. Meyers, Acta Mater. 55 (2007) 13-28.

[35] Z. Horita, T.G. Langdon, Mater. Sci. Eng. A 410 (2005) 422-425.

[36] B. Baretzky, M. D. Baró, G. P. Grabovetskaya, J. Gubicza, M. B. Ivanov, Yu.R. Kolobov, T.G. Langdon, J. Lendvai, A. G. Lipnitskii, A.A. Mazilkin, A.A. Nazarov, J. Nogués, I.A. Ovidko, S. 
G. Protasova, G.I. Raab, Á. Révész, N.V. Skiba, J. Sort, M.J. Starink, B.B. Straumal, S. Suriñach, T. Ungár and A.P. Zhilyaev, Rev. Adv. Mater. Sci. 9 (2005) 45-108.

[37] R.K. Islamgaliev, V.U. Kazyhanov, L.O. Shestakova, A.V. Sharafutdinov, R.Z. Valiev, Mater. Sci. Eng. A 493(2008) 190-194.

[38] M.J. Starink, X.G. Qiao, J.W. Zhang, N. Gao. Acta Mater. 57(2009), 5796-5811.

[39] P. Skjerpe, J. Gjonnes, Y. Langsrud, Ultramicroscopy, 22 (1986) 239-249.

[40] M.W. Meredith, J. Worth, R.G. Hamerton, Mater. Sci. Forum 396-402 (2000) 107-112,

[41] A. Korchef, N. Nabil, C. Yannick, G. Sandrine, L. Cédric, M. Jalel, K. Abdelwaheb, Adv. Eng. Mater. 6 (2004) 222-228.

[42] A. Korchef, N. Nabil, A.W. Kolsi, Cryst. Res. Tech. 44 (2009) 106-110.

[43] D. Markus, P. Florian, M. Johannes, H.H. Werner, J. Mater. Sci. 43 (2008) 7481-7487.

[44] D. Fatay, E. Bastarash, K. Nyilas, S. Dobatkin, J. Gubicza, T. Ungar, Mater. Res. Adv. Tech. 94 (2003) 842-847.

[45] Y. Todaka, M. Umemoto, A. Yamazaki, J. Sasaki, K. Tsuchiya, Mater. Trans. 49 (2008) 47-53.

[46] M.J. Starink, N. Gao, L. Davin, J. Yan, A. Cerezo, Philosoph. Mag. 85 (2005) 1395.

[47] R.K.W. Marceau, G. Sha, S.P. Ringer, in Aluminium Alloys - Their Physical and Mechanical Properties, Volume 1. J. Hirsch, B. Strotzki, G. Gottstein (Eds.), Wiley-VCH Verlag GmbH \& Co. KGaA, Weinheim, 2008, pp. 83-90

[48] S.C. Wang, M.J. Starink, Acta Mater. 55 (2007) 933-941. 